\title{
Publisher Correction: Upregulation of prefrontal metabotropic glutamate receptor 5 mediates neuropathic pain and negative mood symptoms after spinal nerve injury in rats
}
Geehoon Chung $\mathbb{1}^{1,2}$, Chae Young Kim ${ }^{1,3}$, Yeong-Chan Yun ${ }^{1}$, Sang Ho Yoon ${ }^{1,3}$, Myoung-Hwan $\mathrm{Kim}^{1,3}$, Yu Kyeong $\mathrm{Kim}^{4}$ \& Sang Jeong Kim (1) ${ }^{1,2,3,5}$

Correction to: Scientific Reports https://doi.org/10.1038/s41598-017-09991-8, published online 29 August 2017

In the original version of this Article, the authors Chae Young Kim, Sang Ho Yoon, Yu Kyeong Kim and Sang Jeong Kim were incorrectly indexed.

Additionally, the original version of this Article omitted an affiliation for Sang Jeong Kim. The correct affiliations are listed below:

Department of Physiology, Seoul National University College of Medicine, Seoul, Korea

Department of Brain and Cognitive Sciences, Seoul National University College of Natural Sciences, Seoul, Korea

Department of Biomedical Sciences, Seoul National University College of Medicine, Seoul, Korea

Neuroscience Research Institute, Seoul National University College of Medicine, Seoul, Korea

These errors have now been corrected in the HTML and PDF versions of this Article.

(i) Open Access This article is licensed under a Creative Commons Attribution 4.0 International cc. License, which permits use, sharing, adaptation, distribution and reproduction in any medium or format, as long as you give appropriate credit to the original author(s) and the source, provide a link to the Creative Commons license, and indicate if changes were made. The images or other third party material in this article are included in the article's Creative Commons license, unless indicated otherwise in a credit line to the material. If material is not included in the article's Creative Commons license and your intended use is not permitted by statutory regulation or exceeds the permitted use, you will need to obtain permission directly from the copyright holder. To view a copy of this license, visit http://creativecommons.org/licenses/by/4.0/.

(C) The Author(s) 2018

${ }^{1}$ Department of Physiology, Seoul National University College of Medicine, Seoul, Korea. ${ }^{2}$ Department of Brain and Cognitive Sciences, Seoul National University College of Natural Sciences, Seoul, Korea. ${ }^{3}$ Department of Biomedical Sciences, Seoul National University College of Medicine, Seoul, Korea. ${ }^{4}$ Department of Nuclear Medicine, Seoul National University College of Medicine, Seoul, Korea. ${ }^{5}$ Neuroscience Research Institute, Seoul National University College of Medicine, Seoul, Korea. Geehoon Chung and Chae Young Kim contributed equally to this work. Correspondence and requests for materials should be addressed to S.J.K. (email: sangjkim@snu.ac.kr) 